\title{
Clinical efficacy of locoregional therapy prior to living donor liver transplantation for hepatocellular carcinoma based on UCSF criteria
}

\section{Tsung-Han Wu}

Chang Gung Memorial Hospital

\section{Chih-Hsien Cheng}

Chang Gung Memorial Hospital

Chen-Fang Lee

Chang Gung Memorial Hospital

\section{Ting-Jung Wu}

Chang Gung Memorial Hospital

\section{Hong-Shiue Chou}

Chang Gung Memorial Hospital

Kun-Ming Chan ( $\nabla$ chankunming@adm.cgmh.org.tw)

Chang Gung Memorial Hospital Linkou Branch https://orcid.org/0000-0002-7566-0113

\section{Wei-Chen Lee}

Chang Gung Memorial Hospital

\section{Research article}

Keywords: Hepatocellular carcinoma, loco-regional therapy, living donor liver transplantation, outcomes, tumor necrosis

Posted Date: August 19th, 2019

DOI: https://doi.org/10.21203/rs.2.13167/v1

License: (c) (1) This work is licensed under a Creative Commons Attribution 4.0 International License. Read Full License 


\section{Abstract}

Background The study analyzed the loco-regional therapy outcomes prior to living donor liver transplantation (LDLT), to provide additional information for decision-making regarding therapeutic strategy for hepatocellular carcinoma (HCC) patients. Methods A total of 308 consecutive patients undergoing LDLTs for HCC between August 2004 and December 2018 were retrospectively analyzed. Patients subjected to loco-regional therapy prior to LT were grouped and the outcomes were compared. Results Overall, HCC recurrence after LDLT were detected in 38 patients (12.3\%) during the follow-up period. By the end of the study, 205 patients, 6 of whom with recurrent HCC, were alive. Patients who had radiological imaging beyond the University of California at San Francisco (UCSF) criteria had significant inferior outcomes for both recurrence-free survival (RFS, $p=0.0005)$ and overall survival $(O S, p=0.0462)$ despite receiving loco-regional therapy as down-staging intention. Moreover, patients with profound tumor necrosis (TN) had a superior RFS at 3 and 5 years (97.4\% and $93.8 \%$, respectively), compared with others. Conclusion LDLT gains a satisfactory result based on the expanded UCSF criteria for HCC. However, the loco-regional therapy prior to LDLT does not seem to provide benefit unless a profound TN is noted.

\section{Introduction}

Hepatocellular carcinoma (HCC) is a major cause for cancer-related death worldwide, and its management is rapidly evolving during the last decade (1). However, the selection of appropriate treatment for patients with HCC remains a challenge because of the clinical complexity of patients and the variability of treatment efficacy. As such, the concept of HCC treatment has currently embraced a multidisciplinary approach, which remarkably improved the long-term patients' outcome.

Surgical treatments, including liver resection (LR) and liver transplantation (LT), currently provide the greatest opportunity for the potential cure of HCC. Moreover, LT is regarded as the best choice for patients who have liver cirrhosis associated with HCC but ineligible for primary LR, as the transplantation cures the underlying cirrhosis and provides the lowest cancer recurrence rate. Although the Milan Criteria set a gold standard for LT to treat HCC with favorable overall and recurrence-free survival, the strict criteria also limits the range of patients who can receive LT (2). Therefore, numerous alternative, looser criteria have been introduced, showing comparable clinical outcomes than the Milan criteria (3-7).

However, the expansion of selection criteria should be taken cautiously, because HCC recurrence remains a great concern, leading to a poor outcome after LT. By contrast, loco-regional therapy prior to LT might be considered for the purpose of down-staging the tumor, to reduce the risk of progression and dropout of patients on the waiting list, or to improve the possibility of a favorable outcome after LT (8-11). The existing data had shown the effectiveness of loco-regional therapy to improve the outcome after LT, but these results seems to be biased by the robust pathological response to the treatment in certain patients (12-16). Nonetheless, a consensus has not been reached for the timing and the modality of treatment. Additionally, living donor liver transplantation (LDLT) account for the majority of LT events, due to the 
scarcity of organ from deceased donors in most of the Asian countries. Therefore, further investigation of LDLT remains important to optimize therapeutic strategies for patients with HCC. This study enrolled patients who had undergone LDLT for HCC, and further investigated the impact of pre-transplantation loco-regional therapy after LT. Apart from that, we also examined the effect of loco-regional therapy prior to LDLT based on the intention of treatment.

\section{Material And Methods}

\section{Patients}

We retrospectively analyzed all patients who had undergone LDLT for HCC at the Organ Transplantation Institute of Chang Gung Memorial Hospital at Linkou, Taiwan, between August 2004 and December 2008. The study was approved by the Institutional Review Broad, and included a total of 308 consecutive patients with pathologically proven of HCC through histological examination of the explant liver. Subsequently, patients subjected to loco-regional therapy prior to LT were grouped and the outcomes were compared with those of the group of patients who did not undergo the therapy.

\section{HCC evaluation and management before transplantation}

The diagnosis of HCC was based on the European Association for the Study of the Liver (EASL) and American Association for the Study of Liver Diseases (AASLD) guidelines $(17,18)$. The treatment of HCC is mainly based on the algorithm of the Barcelona Clinic Liver Cancer (BCLC) staging system. In line with the current practices for HCC, the treatment modality options were multidisciplinary and depended on patient's performance, cirrhotic status of the liver, and the tumor characteristics (1). In particular, liver resection is always considered the preferred treatment for HCC. Patients with HCC ineligible to liver resection and willing to undergo transplantation were evaluated for LT eligibility. The transplantation criteria for HCC were based on the University of California at San Francisco (UCSF) criteria, that use radiological imaging evidence in terms of tumor number and size (7).

Based on the clinical context, we divided patients with HCC waiting to receive LT in three groups. Group I comprised patients who had not received any loco-regional therapy for HCC before LDLT. Group II comprised patients who had unresectable HCC and met the UCSF radiological criteria (rUCSF), but were unable to receive LT immediately due to the availability of donors or hesitation about LT surgery. These patients would thus be recommended for loco-regional therapy in order to reduce the risk of tumor progression. Group III comprised patients who had a HCC beyond rUCSF criteria, and for whom we performed loco-regional therapy for the purpose of down-staging.

\section{Liver transplantation and follow-up}


All LDLT procedures were performed using standard techniques and without venous bypass. The immunosuppressant regimen consisted of calcineurin inhibitors, antimetabolites, and steroid as previous described (13). After transplantation, the explanted livers were subjected to a thorough histological examination to determine the HCC pathological characteristics. All patients were re-assessed for HCC in terms of tumor number and size for meeting transplantation criteria based on pathological results established in the UCSF guidelines.

After LDLT, patients were regularly followed-up for graft function and tumor recurrence in the department. Generally, liver ultrasonography was performed in a minimum of 3-month intervals, and radiological imaging including computed tomography (CT) and/or MRI was routinely performed at 1, 3, 6, and 12 months of the first year and annually afterward or whenever there was suspicion of HCC recurrence.

\section{Outcome and statistical analysis}

The outcome assessments included HCC recurrence-free survival (RFS) and the patients overall survival (OS). RFS was measured from the date of LDLT to the detection of HCC recurrence, while OS was calculated from the date of LDLT to the death of patient or until the end of this study. The survival curves were generated using the Kaplan-Meier method and compared using the log-rank test. The categorical clinic-pathological variables were analyzed using the $\chi 2$ or Fisher exact test as appropriate; continuous variables are presented as median and range followed by comparison using the Student's $t$ test. All statistical analyses were performed using the SPSS statistical software package version 25.0 (SPSS, Inc., Chicago, IL, USA) for Windows. A p-value of less than 0.05 was considered statistically significant.

\section{Results}

\section{General outcomes of patients}

Among 738 LDLT events, 308 patients (41.7\%), of whom 249 were males and 59 were females, were confirmed to have HCC and were included in this study. Based on the aforementioned grouping criteria, 52 patients (16.9\%) were in Group I, 228 patients (74.0\%) were in Group II, and the remaining 28 patients (9.1\%) were in Group III. During the follow-up, we detected HCC recurrence in 38 patients $(12.3 \%)$ in a period from 1.2 to 92.5 months after LT (median, 15.0 months). Overall, 103 patients (33.4\%) died during the study, of which 17 were hospital mortalities (5.5\%) within 3 months, and 30 patients died of HCC recurrence after LDLT. The remaining 205 alive patients included 6 patients with recurrent HCC and 199 HCC-free patients at the end of this study.

\section{Group comparison}

The clinical features of the patient groups are summarized in Table 1. Generally, the majority of clinical features were similar between groups. As group III represented HCC beyond radiological UCSF criteria for 
transplantation, their tumor characteristics in terms of number and size were significantly more aggressive than the other two groups. However, the severity of liver cirrhosis and the Model for End-Stage Liver Disease (MELD) score was significantly higher in group I. Specifically, $21.2 \%$ and $24.6 \%$ of patients in group I and group II, respectively, were pathologically beyond UCSF criteria, which did not correlate with radiological criteria before LDLT. Similarly, after pathological examination, $21.4 \%$ of patients within group III were within UCSF criteria.

The comparison of survival curves showed that both RFS (Fig. 1, $p=0.0005$ ) and OS (Fig. 2, $p=0.0462$ ) were significantly different between the 3 groups. Moreover, the subgroup analysis showed that group III had significant poorer outcomes (5-years RFS and OS of $54.7 \%$ and $56.2 \%$, respectively) compared with group I (90.0\%, and 62.7\%) and group II (88.2\%, and 73.3\%). However, RFS and OS outcomes between group I and II were statistically similar.

\section{Outcome associated with loco-regional therapy}

Subsequently, patients who had received loco-regional therapy were further pathologically examined for effectiveness in relation to the degree of tumor necrosis (TN) as previous described (13). We defined a mean TN higher than $60 \%$ as profound $\mathrm{TN}$, and patients with loco-regional therapy were further compared based on this definition. A total of 85 patients undergoing loco-regional therapy prior to LDLT, accounting for $33.2 \%$ of all patients, were had profound TN.

The clinico-pathological features of patients regarding the TN status were compared in Table 2. The serum level of AFP was significantly higher in patients who were unable to get profound TN, as well as the size and number of the HCC features. However, loco-regional therapy did not results in a significant difference between the two patient groups. Among patients with a profound TN, we observed a higher percentage of patients who were within the radiological and pathological UCSF criteria.

Based on the definition of profound TN, we compared the RFS and OS curves of patients who had profound TN and patients who did not. The RFS of patients with profound TN at 1, 3, and 5 years were $98.7 \%, 97.4 \%$, and $93.8 \%$, respectively, whereas the RFS of patients without profound TN at the same time points were $90.7 \%, 81.5 \%$, and $79.7 \%$ (Fig. 3, $p=0.01$ ). Moreover, the comparison of OS curves between these two groups were also not significant: the cumulative OS of patients with profound TN at 1, 3, and 5 years were $88.2 \%, 86.7 \%$, and $82.0 \%$, respectively, while the OS of patients without profound TN were $83.5 \%, 72.5 \%$, and $66.4 \%$, respectively. (Fig. $4, p=0.17$ )

\section{Discussion}

Since the first successful LT performed by Thomas E. Starzl half a century ago, LT has become a common and routine operation in many transplantation centers worldwide. Moreover, a flourishing LDLT practice, accounting for the majority of LT, evolved in East Asia as a result of growing experiences and due to the scarcity of deceased donors(19). Currently, LT has become the ideal curative treatment for liver 
cirrhosis associated with HCC as it simultaneously removes the tumors and cures the underlying liver cirrhosis that provides a pathogenic environment for the occurrence of HCC. As such, LDLT offers a flexible timely transplantation possibility, providing a defining timeframe prepare the recipient before the operation. Theoretically, performing a pre-operative treatment might ameliorate the aggressiveness of HCC and improve the overall patient's outcome. Therefore, the present study analyzed patients who underwent LDLT for HCC to investigate the outcome in relation to the pre-transplantation loco-regional therapy. According to this study, the outcome of LDLT for patient with HCC was satisfactory, with a favorable RFS rate. However, performing loco-regional therapy prior to LDLT seems to not provide beneficial outcome unless a certain effect of loco-regional therapy prior to LT is achieved.

Although the treatment algorithm based on BCLC staging is very clear, the optimal treatment modality selection for patient with unresectable HCC remains uncertain as too many options are available, depending on complex clinical decision. Moreover, after general consideration of information about therapeutic options, importance of benefits, harms, and uncertainties of available options, individual patient may have their own choice of treatment in a shared decision making process (20). It is a good practice for a care provider to inform patients of all risks involved with a certain treatment instead of forcing a treatment. Therefore, patients with unresectable HCC would be evaluated for LT in the institute only if the patient was willing to undergo transplantation. Additionally, the scarcity of donor remains the major concern for LT: thus, the majority of patients received loco-regional therapy prior to LDLT due to the lack of available donor for immediate transplantation. Additionally, patients might be initially listed for waiting for a deceased donor liver transplant (DDLT) and turned to LDLT because of the long-time waiting and the fear of tumor progression. In those patients, loco-regional therapy was mostly performed in order to reduce the risk of tumor progression outside the transplantation criteria.

Generally, the living donor liver graft is a dedicated gift from a recipient's relative, not competing with other patients awaiting for LT. LDLT usually offers a flexible timing for transplantation depending on the clinical scenario, the disease severity, and the preparation of available donor. In particular, the majority of patients with HCC have a low MELD score, meaning a non-life-threatening physical condition without a LT in a few weeks. The timeframe between the initiation of donor survey and matchup to LDLT in the institute is no longer than 4 weeks. Therefore, a planned loco-regional therapy with such a short-term treatment seems unnecessary nor giving beneficial effects.

In line with the previous studies, profound TN was observed in those patients who had less aggressive HCC, lower AFP, a lower tumor number, and smaller tumor size $(13,14,21)$. However, in the current clinical setting, modality, timing and frequency of loco-regional therapy to achieve a profound TN response remain uncertain. Additionally, it is difficult to assess TN through radiological imaging scan, and it could only be confirmed with thoroughly examination of the explanted liver after LT. Hence, it is unpractical to adjust the optimal treatment strategy for LDLT on the basis of loco-regional therapy efficacy in terms of TN. Apart from that, radiological imaging scan could be mis-staging HCC: this study, radiological images of nearly $20 \%$ of all the patients did not correlate to pathological staging. Moreover, interpret the radiological image of a cirrhotic liver is more difficult after loco-regional therapy. Nonetheless, despite the 
aforementioned concerns, loco-regional therapy for HCC patient awaiting LT remains an international golden standard for the management of HCC patients during the waiting time $(22,23)$. Loco-regional therapy prior to LT might be insufficient for achieving a better outcome but still encouraged as long as the patient is suitable for such treatment.

Although in this study LDLT for patients with HCC reached satisfactory results, the patients who were initially beyond the rUCSF criteria had a higher incidence of HCC recurrence after transplantation, compared with the other two groups. However, the outcomes related to the use of pre-transplantation loco-regional therapy were not statistically different in this study. Currently, the UCSF criteria are widely accepted to justify LT for HCC, demonstrating favorable long-term results. In this study, the low incidence of HCC recurrence might explain the lack of significant differences between the group I and II. Additionally, the majority of group II patients only received one round of loco-regional therapy: thus, it seems that achieving a profound or complete TN is improbable. Generally, loco-regional therapy before LT is mostly performed to prevent tumor progression in a long waiting time period, and the increased number of treatment could either reflect a long waiting time or a further tumor progression. However, a randomized controlled trial comparing patients treated with and without loco-regional therapy before LT may not be practical because of ethical concerns as well as the increased risk of tumor progression in certain study group. Therefore, we are still unable to establish a definitive therapeutic protocol to achieve a beneficial outcome of HCC patients after LT.

Although this study might be limited by using a retrospective cohort, we also provide helpful information for planning a therapeutic strategy for patients with HCC awaiting to receive LDLT. Recently, two studies reported that LDLT gave a better survival benefit for patients with $\operatorname{HCC}$ compared with $\operatorname{DDLT}(24,25)$. However, the nature between LDLT and DDLT for patients with HCC might be existing differences despite having the same goal to cure HCC. A recent big data analysis of DDLT in patients with HCC showed that the use of loco-regional therapy could improve survival and reduce recurrence only in patients who achieve a complete pathological response (14). Nonetheless, this study showed that also achieving profound TN rather than complete pathological response by loco-regional therapy could offer better outcomes. Our discoveries perhaps provide additional information in the difficult challenge to optimize therapeutic strategies for patients with HCC.

\section{Abbreviations}

HCC: hepatocellular carcinoma, LT: liver transplantation, LDLT: living donor liver transplantation, UCSF: University of California at San Francisco, CT: computed tomography, MRI: magnetic resonance imaging, RFS: recurrence-free survival, OS: overall survival.

\section{Declarations}

Ethics, consent and permission: 
This study was fully approved by the internal review board of Chang Gung Memorial Hospital at Linkou (Approval No.: 98-3794B), and informed consent from patient was waived due to its retrospective nature.

\section{Consent for publication}

Not applicable

\section{Availability of data and materials:}

All data generated or analysed during this study are included in this published article.

\section{Conflict-of-interest statement:}

The authors have no conflicts of interest.

\section{Funding:}

None

\section{Authors' contributions:}

Manuscript drafting: Tsung-Han Wu

Study concept, design, and manuscript editing: Kun-Ming Chan

Acquisition of data: Kun-Ming Chan, Tsung-Han Wu, Chih-Hsien Cheng, Chen-Fang Lee, Ting-Jung Wu, Hong-Shiue Chou, Wei-Chen Lee

Critical revision of the manuscript for important intellectual content: Kun-Ming Chan, Wei-Chen Lee

\section{Acknowledgments:}

The authors would like to thank Ms. Shu-Fang Huang from Department of General Surgery, Chang Gung Memorial Hospital at Linkou for the statistical support.

\section{References}

1.Dhir M, Melin AA, Douaiher J, Lin C, Zhen WK, Hussain SM, et al. A Review and Update of Treatment Options and Controversies in the Management of Hepatocellular Carcinoma. Ann Surg. 
2.Mazzaferro V, Regalia E Fau - Doci R, Doci R Fau - Andreola S, Andreola S Fau - Pulvirenti A, Pulvirenti A Fau - Bozzetti F, Bozzetti F Fau - Montalto F, et al. Liver transplantation for the treatment of small hepatocellular carcinomas in patients with cirrhosis. N Engl J Med. 1996;334:693-9.

3.DuBay D, Sandroussi C, Sandhu L, Cleary S, Guba M, Cattral MS, et al. Liver transplantation for advanced hepatocellular carcinoma using poor tumor differentiation on biopsy as an exclusion criterion. Ann Surg. 2011;253(1):166-72.

4.Lee S, Ahn C, Ha T, Moon D, Choi K, Song G, et al. Liver transplantation for hepatocellular carcinoma: Korean experience. J Hepatobiliary Pancreat Sci. 2010;17(5):539-47.

5.Mazzaferro V, Llovet JM, Miceli R, Bhoori S, Schiavo M, Mariani L, et al. Predicting survival after liver transplantation in patients with hepatocellular carcinoma beyond the Milan criteria: a retrospective, exploratory analysis. Lancet Oncol. 2009;10(1):35-43.

6.Sugawara Y, Tamura S, Makuuchi M. Living donor liver transplantation for hepatocellular carcinoma: Tokyo University series. Dig Dis. 2007;25(4):310-2.

7.Yao FY, Ferrell L, Bass NM, Watson JJ, Bacchetti P, Venook A, et al. Liver transplantation for hepatocellular carcinoma: expansion of the tumor size limits does not adversely impact survival. Hepatology. 2001;33(6):1394-403.

8.Clavien P-A, Lesurtel M, Bossuyt PMM, Gores GJ, Langer B, Perrier A. Recommendations for liver transplantation for hepatocellular carcinoma: an international consensus conference report. The Lancet Oncology. 2012;13(1):e11-e22.

9.Lesurtel M, Mullhaupt B, Pestalozzi BC, Pfammatter T, Clavien PA. Transarterial chemoembolization as a bridge to liver transplantation for hepatocellular carcinoma: an evidence-based analysis. Am J Transplant. 2006;6(11):2644-50.

10.Lu DS, Yu NC, Raman SS, Lassman C, Tong MJ, Britten C, et al. Percutaneous radiofrequency ablation of hepatocellular carcinoma as a bridge to liver transplantation. Hepatology. 2005;41(5):1130-7.

11.Cucchetti A, Cescon M, Bigonzi E, Piscaglia F, Golfieri R, Ercolani G, et al. Priority of candidates with hepatocellular carcinoma awaiting liver transplantation can be reduced after successful bridge therapy. Liver Transpl. 2011;17(11):1344-54.

12.Millonig G, Graziadei IW, Freund MC, Jaschke W, Stadlmann S, Ladurner R, et al. Response to preoperative chemoembolization correlates with outcome after liver transplantation in patients with hepatocellular carcinoma. Liver Transpl. 2007;13(2):272-9. 
13.Chan KM, Yu MC, Chou HS, Wu TJ, Lee CF, Lee WC. Significance of tumor necrosis for outcome of patients with hepatocellular carcinoma receiving locoregional therapy prior to liver transplantation. Ann Surg Oncol. 2011;18(9):2638-46.

14.Agopian VG, Harlander-Locke MP, Ruiz RM, Klintmalm GB, Senguttuvan S, Florman SS, et al. Impact of Pretransplant Bridging Locoregional Therapy for Patients With Hepatocellular Carcinoma Within Milan Criteria Undergoing Liver Transplantation: Analysis of 3601 Patients From the US Multicenter HCC Transplant Consortium. Ann Surg. 2017;266(3):525-35.

15.Na GH, Kim EY, Hong TH, You YK, Kim DG. Effects of loco regional treatments before living donor liver transplantation on overall survival and recurrence-free survival in South Korean patients with hepatocellular carcinoma. HPB (Oxford). 2016;18(1):98-106.

16. Halazun KJ, Tabrizian P, Najjar M, Florman S, Schwartz M, Michelassi F, et al. Is it Time to Abandon the Milan Criteria?: Results of a Bicoastal US Collaboration to Redefine Hepatocellular Carcinoma Liver Transplantation Selection Policies. Ann Surg. 2018.

17.Bruix J, Sherman M, American Association for the Study of Liver D. Management of hepatocellular carcinoma: an update. Hepatology. 2011;53(3):1020-2.

18.Llovet JM, Ducreux M. EASL-EORTC clinical practice guidelines: management of hepatocellular carcinoma. J Hepatol. 2012;56(4):908-43.

19.Chen CL, Kabiling CS, Concejero AM. Why does living donor liver transplantation flourish in Asia? Nat Rev Gastroenterol Hepatol. 2013;10(12):746-51.

20.0p den Dries S, Annema C, Berg AP, Ranchor AV, Porte RJ. Shared decision making in transplantation: how patients see their role in the decision process of accepting a donor liver. Liver Transpl. 2014;20(9):1072-80.

21.Merani S, Majno P, Kneteman NM, Berney T, Morel P, Mentha G, et al. The impact of waiting list alphafetoprotein changes on the outcome of liver transplant for hepatocellular carcinoma. J Hepatol. 2011;55(4):814-9.

22.Clavien PA, Lesurtel M, Bossuyt PM, Gores GJ, Langer B, Perrier A, et al. Recommendations for liver transplantation for hepatocellular carcinoma: an international consensus conference report. Lancet Oncol. 2012;13(1):e11-22.

23.Kim SH, Lee EC, Park SJ. Pretransplant locoregional therapy for hepatocellular carcinoma: encouraging but insufficient. Hepatobiliary Surg Nutr. 2018;7(2):136-7.

24.Goldaracena N, Gorgen A, Doyle A, Hansen BE, Tomiyama K, Zhang W, et al. Live donor liver transplantation for patients with hepatocellular carcinoma offers increased survival vs. deceased donation. J Hepatol. 2019;70(4):666-73. 
25.Wong TCL, Ng KKC, Fung JYY, Chan AAC, Cheung TT, Chok KSH, et al. Long-Term Survival Outcome Between Living Donor and Deceased Donor Liver Transplant for Hepatocellular Carcinoma: Intention-toTreat and Propensity Score Matching Analyses. Ann Surg Oncol. 2019;26(5):1454-62.

\section{Tables}

Table 1. The clinical features of patients based on the intention of loco-regional therapy before living donor liver transplantation.

\begin{tabular}{|c|c|c|c|c|}
\hline & $\begin{array}{l}\text { Group I } \\
(n=52)\end{array}$ & $\begin{array}{l}\text { Group II } \\
(n=228)\end{array}$ & $\begin{array}{c}\text { Group III } \\
(n=28)\end{array}$ & $p$ value \\
\hline Age, median (range) & $58(13-70)$ & $56(33-69)$ & $56(38-69)$ & 0.246 \\
\hline 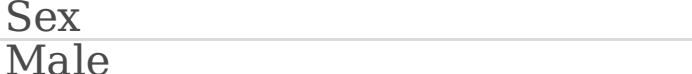 & $39(75.0)$ & $186(81.6)$ & $24(857)$ & 0.437 \\
\hline Female & $13(25.0)$ & $42(18.4)$ & $4(14.3)$ & \\
\hline Hepatitis status & & & & \\
\hline Hepatitis B positive & $25(48.1)$ & $152(66.7)$ & $19(67.9)$ & 0.181 \\
\hline Hepatitis C positive & $17(32.7)$ & $51(22.4)$ & $7(25.0)$ & \\
\hline $\mathrm{HBV}+\mathrm{HCV}$ & $6(11.5)$ & $10(4.4)$ & $1(3.6)$ & \\
\hline None & $4(7.7)$ & $15(6.6)$ & $1(3.6)$ & \\
\hline MELD score, median (range) & $15.5(8-36)$ & $10.0(6-35)$ & $9.5(5-22)$ & 00001 \\
\hline Child Class & & & & 0.0001 \\
\hline A & $9(17.3)$ & $116(50.9)$ & $16(57.1)$ & \\
\hline B & 17 (32.7) & 81 (35.5) & $8(28.6)$ & \\
\hline $\mathrm{C}$ & $26(50.0)$ & 31 (13.6) & $4(14.3)$ & \\
\hline AFP, median (range) & $\begin{array}{l}9.2(2.0- \\
1552)\end{array}$ & $\begin{array}{l}11.8(1.3- \\
18250)\end{array}$ & $\begin{array}{l}53.4(2.0- \\
461)\end{array}$ & 0.098 \\
\hline Graft type & & & & 0.578 \\
\hline Left liver & $2(3.8)$ & $16(7.0)$ & $1(3.6)$ & \\
\hline Right liver & $50(96.2)$ & $212(93.0)$ & 27 (96.4) & \\
\hline GRWR (\%) & & & & 0.037 \\
\hline$\leq 0.8$ & $7(13.5)$ & $64(28.1)$ & $4(14.3)$ & \\
\hline Tumor Number, median (range) & $1(1-20)$ & $\begin{array}{l}164(71.9) \\
2(1-22)\end{array}$ & $\begin{array}{l}24(85.7) \\
4(1-20)\end{array}$ & $<0$ \\
\hline $\begin{array}{l}\text { Maximum tumor size, median } \\
\text { (range) }\end{array}$ & $2.1(1.0-7.5)$ & $2.5(1.0-9.2)$ & $\begin{array}{l}3.4(1.5- \\
11.2)\end{array}$ & 0.006 \\
\hline Pathologic UCSF & & & & 0.0001 \\
\hline Within & $41(78.8)$ & $172(75.4)$ & $6(21.4)$ & \\
\hline Beyond & $11(21.2)$ & $56(24.6)$ & $22(78.6)$ & \\
\hline $\begin{array}{c}\text { Histology grade } \\
1-2\end{array}$ & $13(8$ & 160 & 1) & 0.382 \\
\hline 3-4 & $9(17.3)$ & $59(25.9)$ & $8(28.6)$ & \\
\hline
\end{tabular}

HBV, hepatitis B virus; HCV, hepatitis C virus; MELD, model for end-stage liver disease; AFP, alpha-fetoprotein; GRWR; graft recipient weight ratio; UCSF, University of California San Francisco. 
Table 2. Clinical characteristics of patients associated with pre-transplantation locoregional therapy according to the presence of profound tumor necrosis. $(n=256)$

\begin{tabular}{|c|c|c|c|}
\hline & \multicolumn{2}{|c|}{ Profound tumor necrosis ( $\geq 60 \%)$} & \multirow[b]{2}{*}{$\mathrm{p}$ value } \\
\hline & With $(n=85)$ & Without $(n=171)$ & \\
\hline Age, median (range) & $55(33-67)$ & $56(33-69)$ & \multirow{3}{*}{$\begin{array}{l}0.177 \\
0.198\end{array}$} \\
\hline Male & $66(77.6)$ & $144(84.2)$ & \\
\hline Female & $19(22.4)$ & $27(15.8)$ & \\
\hline Hepatitis status & & & \multirow[t]{4}{*}{0.834} \\
\hline Hepatitis B positive & $54(63.5)$ & $117(68.4)$ & \\
\hline $\begin{array}{l}\text { Hepatitis C positive } \\
\mathrm{HBV}+\mathrm{HCV}\end{array}$ & $\begin{aligned} & 22(25.9) \\
& 4(4.7)\end{aligned}$ & $\begin{array}{l}36(21.1) \\
7(4.1)\end{array}$ & \\
\hline None & $5(5.9)$ & $11(6.4)$ & \\
\hline MELD score, median (range) & $11(6-27)$ & $10(5-35)$ & \multirow{4}{*}{$\begin{array}{l}0236 \\
0.460\end{array}$} \\
\hline \multicolumn{3}{|l|}{ Child Class } & \\
\hline $\begin{array}{l}\mathrm{A} \\
\mathrm{B}\end{array}$ & $\begin{array}{l}46(47.1) \\
34(40.0)\end{array}$ & $\begin{array}{l}92(53.8) \\
55(32.2)\end{array}$ & \\
\hline $\mathrm{C}$ & $11(12.9)$ & $24(14.0)$ & \\
\hline AFP, median (range) & $9.0(1.7-1300)$ & $14.9(1.3-18250)$ & \multirow{5}{*}{$\begin{array}{c}0.018 \\
<0.0001 \\
0.011 \\
0.756\end{array}$} \\
\hline Tumor Number, median (range) & $1(1-7)$ & $3(1-22)$ & \\
\hline Maximum tumor size, median (range) & $2.0(0.7-7.0)$ & $2.6(0.5-11.2)$ & \\
\hline \multicolumn{3}{|l|}{$\begin{array}{l}\text { Loco-regonal therapy } \\
\text { Within } 3 \text { months }\end{array}$} & \\
\hline $\begin{array}{l}\text { Within } 3 \text { months } \\
\text { Beyond } 3 \text { months }\end{array}$ & $\begin{array}{l}45(52.9) \\
40(47.1)\end{array}$ & $\begin{array}{l}87(50.9) \\
84(49.1)\end{array}$ & \\
\hline \multicolumn{3}{|l|}{ Loco-regional therapy modality } & \multirow[t]{3}{*}{0.145} \\
\hline $\begin{array}{l}\text { Local ablation } \\
\text { TACE }\end{array}$ & $\begin{array}{l}12(14.1) \\
63(74.1)\end{array}$ & $\begin{array}{c}16(9.4) \\
144(84.2)\end{array}$ & \\
\hline TACE+ablation & $10(11.8)$ & $11(6.4)$ & \\
\hline Number of loco-regional therapy & $1(1-17)$ & $1(1-16)$ & \multirow{3}{*}{$\begin{array}{l}0.084 \\
0.007\end{array}$} \\
\hline \multirow{2}{*}{$\begin{array}{l}\text { Radiologic UCSF } \\
\text { Within } \\
\text { Bevond }\end{array}$} & & & \\
\hline & $\begin{aligned} 82 & (96.5) \\
3 & (3.5)\end{aligned}$ & $\begin{array}{l}146(85.4) \\
25(14.6)\end{array}$ & \\
\hline \multirow{3}{*}{$\begin{array}{l}\text { Pathologic UCSF } \\
\text { Within } \\
\text { Beyond }\end{array}$} & & & \multirow[t]{3}{*}{$<0.0001$} \\
\hline & $75(88.2)$ & $103(60.2)$ & \\
\hline & $10(11.8)$ & $68(39.8)$ & \\
\hline
\end{tabular}

HBV, hepatitis B virus; HCV, hepatitis C virus; AFP, alpha-fetoprotein; TACE, transcatheter arterial chemoembolization; UCSF, University of California San Francisco.

\section{Figures}




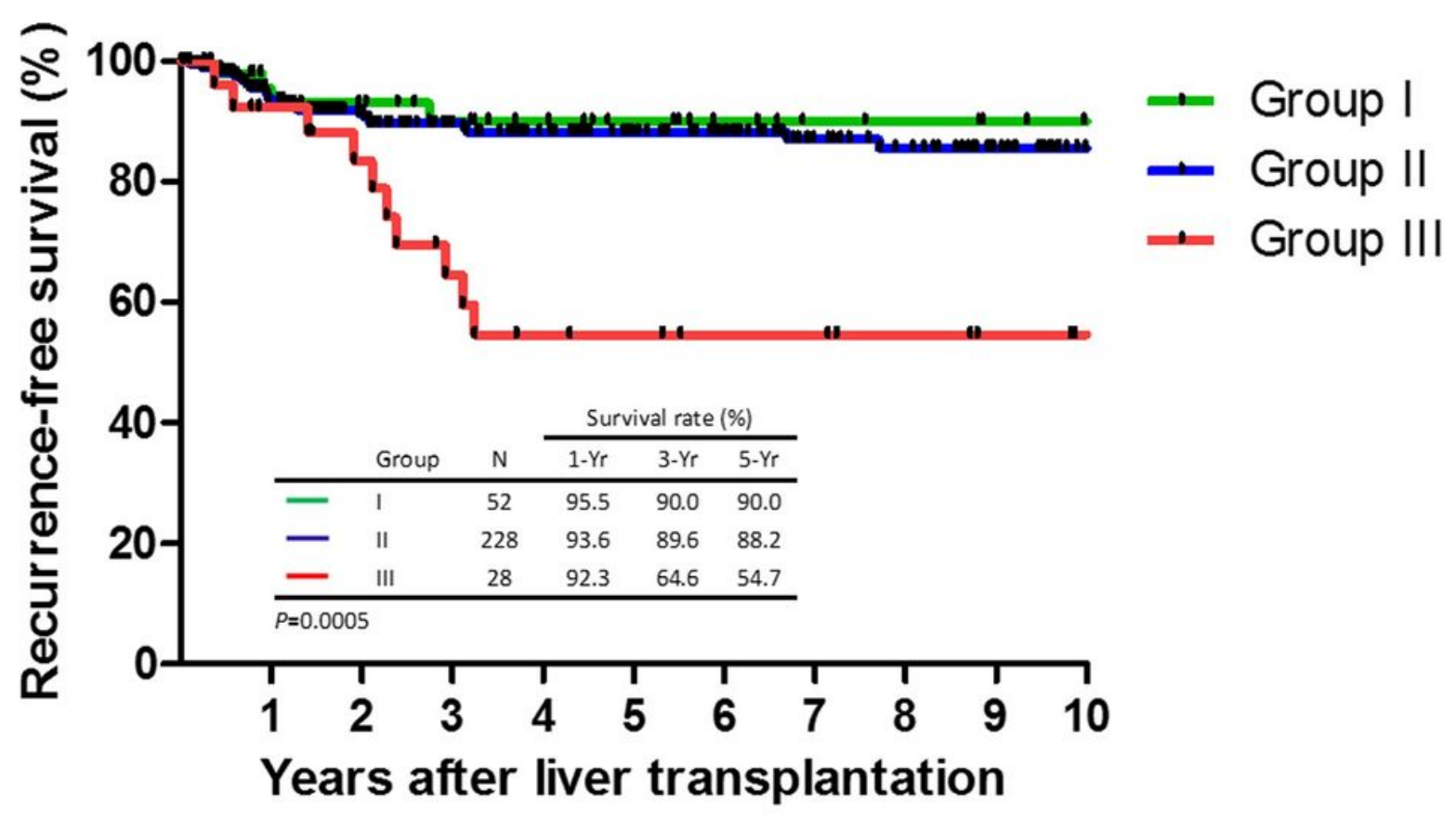

Figure 1

Comparison of recurrence-free survival (RFS) curves between groups. Patients in group III have significant inferior survival curves compared with the other two groups. The 5-years RFS rate of Group III was 54.7\% $(p=0.0005)$. 


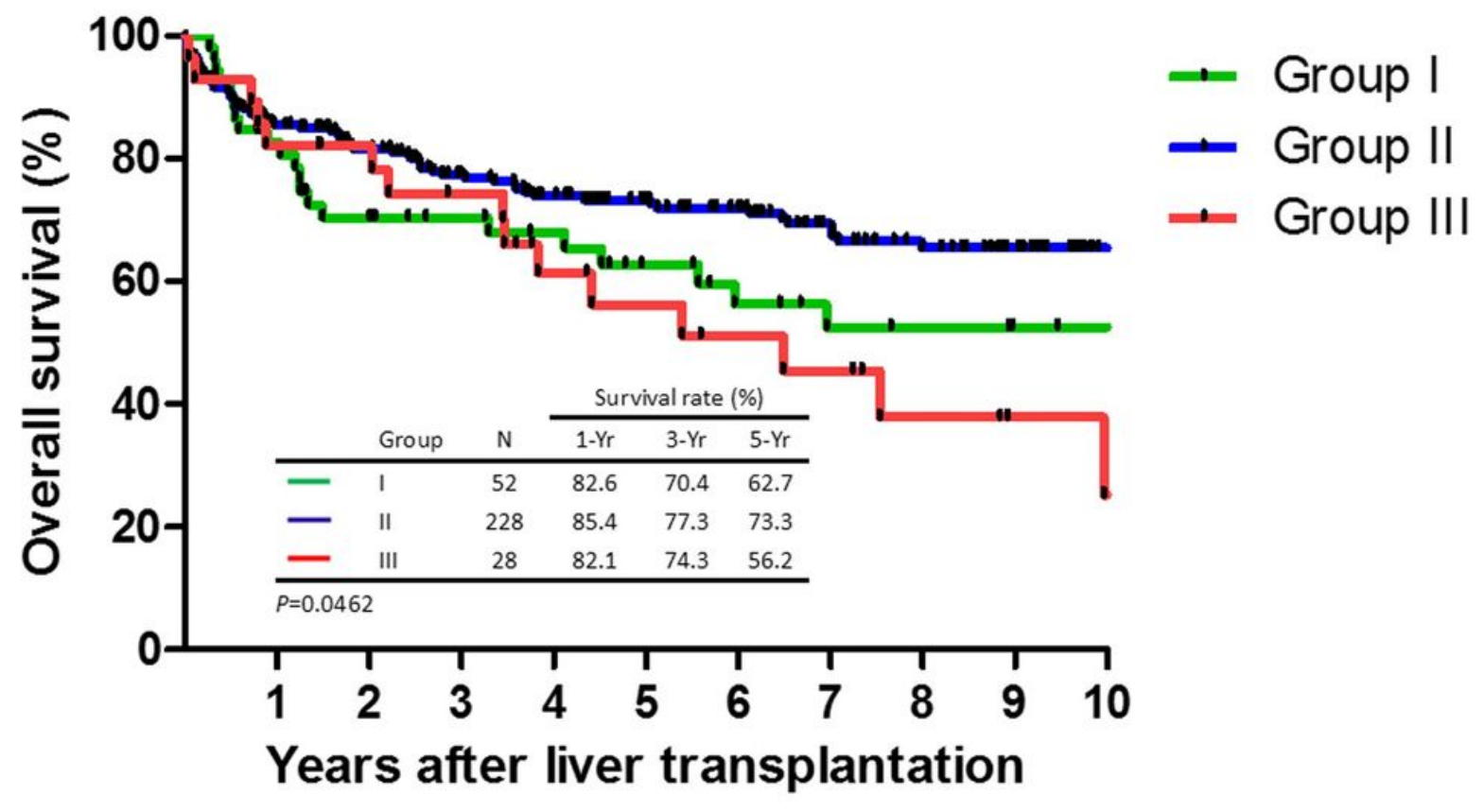

Figure 2

Comparison of overall survival (OS) curves between groups. Patients in group III have significant inferior survival curves compared with the other two groups. The 5-years OS rate of Group III was $56.2 \%$ ( $p=$ 0.0462). 


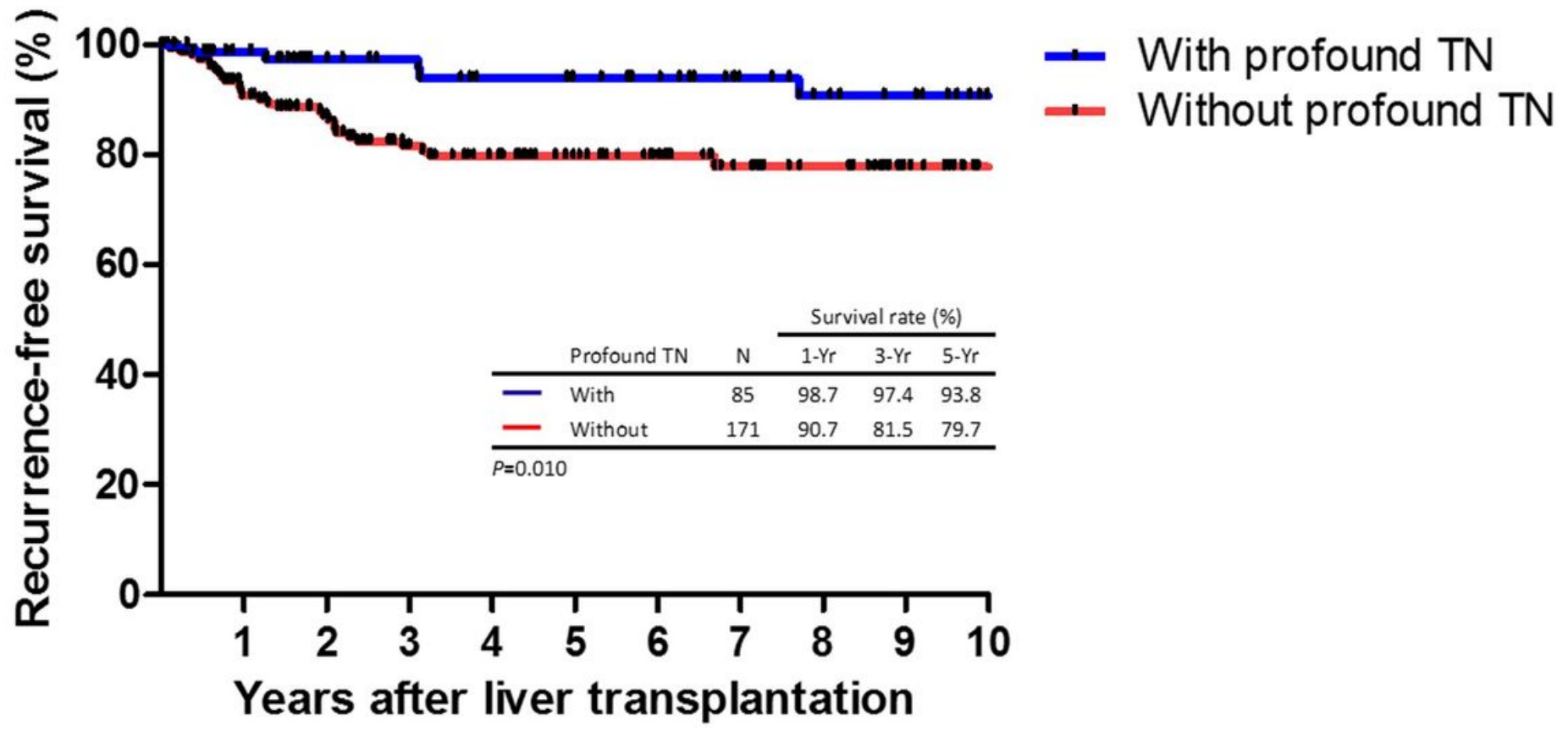

Figure 3

Comparison of recurrence-free survival (RFS) curves based on the definition of profound TN. The RFS in patients with profound TN was significantly better than those without profound TN $(p=0.01)$.

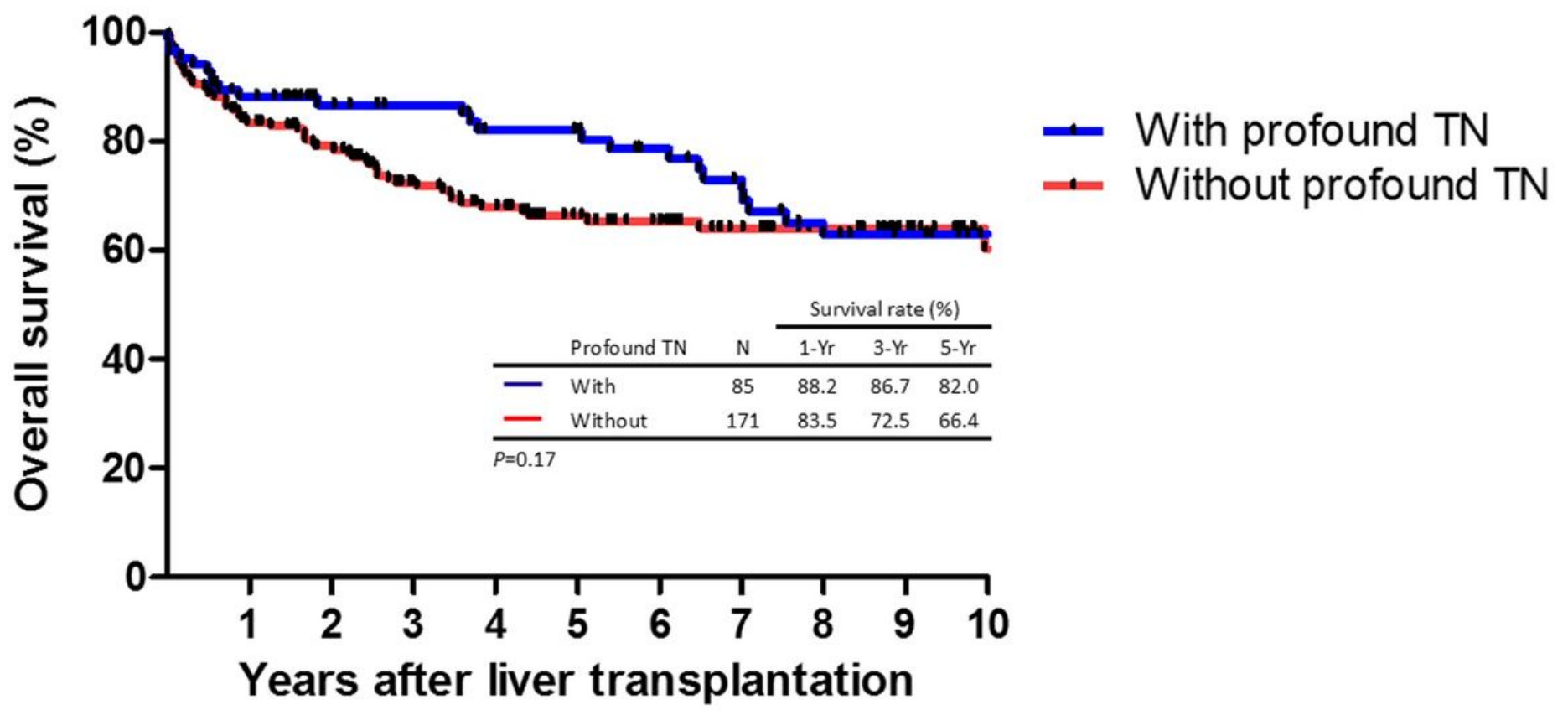


Figure 4

Comparison of overall survival (OS) curves based on the definition of profound TN. The comparison of OS curves was not significantly different in relation to the presence of profound TN $(p=0.17)$. 